\title{
Number Processing Dissociations: Evidence from a Case of Dyscalculia
}

\author{
Fernando Cuetos* and Graciela Miera \\ University of Oviedo
}

In this case study of an aphasic patient with difficulties in numerical processing, the patient responded to a series of linguistic and numerical tasks designed to assess efficiency levels in processing various linguistic components. In addition, the patient completed a series of transcoding tasks that were directed at isolating whether the problems were associated primarily with arabic numerals or with other modalities (spoken or written). Data were analyzed using chi-square goodness-of-fit tests. Statistically significant differences were obtained between spoken verbal and written verbal outpats and between arabic and spoken verbal outputs. Based upon an analysis of errors, it was tentatively concluded that the disorders were associated with two types of dissociation operating together, one between spoken verbal and written verbal outputs at the syntactical level and the other between lexical and syntactical components in the spoken verbal output. A revised model is proposed to provide a tentative explanation for these observations.

Key words: dyscalculia, numeral processing, arabic numeral system

\begin{abstract}
Los estudios realizados en los últimos años con pacientes discalcúlicos están sirviendo para comprobar, por una parte, cómo funcionan los módulos que componen el sistema de procesamiento numérico, y, por otra, la relación que existe entre procesamiento numérico y procesamiento lingüistico en general. En este articulo presentamos un paciente con dificultades en el procesamiento numérico al que se le pasaron varias tareas lingüísticas y numéricas destinadas a comprobar si sus problemas eran sólo numéricos o afectaban también a otras modalidades verbales. Las diferencias estadísticamente significativas (contrastadas mediante chi-cuadrado) entre producción verbal y escrita y entre producción verbal y arábiga y los tipos de errores que comete manifiestan la existencia de dos importantes disociaciones: una en producción arábiga entre los procesos léxico y sintáctico, y otra entre producción verbal y escrita a nivel léxico. Puesto que los modelos existentes no contemplan estas disociaciones, se propone un nuevo modelo derivado de los anteriores.
\end{abstract}

Palabras clave: discalculia, procesamiento numérico, sistema numeral arábigo

This work was supported by a grant from the University of Oviedo, number DF-93-206-20.

* Correspondence concerning this article should be addressed to Dr. Fernando Cuetos, Departamento de Psicología. Universidad de Oviedo. Plaza Feijoo, s/n. 33003 - Oviedo (Spain). 
In the last 20 years, there has been substantial progress in our understanding of the linguistic processing system resulting primarily from the study of individual aphasic patients. The analysis of dissociations, and particularly double dissociations, has allowed for the discrimination of different processes which participate in language, both spoken and written. Recently, similar work has been carried out with dyscalculic patients.

One of the first aims of the research with dyscalculic patients, and more specifically with patients presenting difficulties in numerical processing, was to identify which components make up the number processing system and how they work, both in people who have suffered brain damage and in normal subjects. Detailed analysis of different tasks for individual cases as well as comparisons of these findings with those obtained from other patients have been used to generate models of number processing. Basically, there are two bodies of evidence offered by cognitive neuropsychologists suggesting that the processes associated with comprehension are different from those used in the production of arabic numerals: (1) studies which have revealed the dissociation between these two processes (Cipolotti, Butterworth, \& Warrington, 1994; McCloskey, Sokol, \& Goodman, 1986) and (2) research efforts that have focused on the dissociations between the lexical and syntactic processes in the understanding and production of arabic numerals (Cipolotti et al., 1994; McCloskey \& Caramazza, 1987; Nöel \& Seron, 1993).

As a result of these investigations, several models have been proposed which attempt to account for the number processing system. Only a brief outline of each model is offered because excellent, recent publications are available
(Cipolotti \& Butterworth, 1995; Seron \& Nöel, 1995). In the following paragraphs, several models are addressed: (a) a system of asemantic algorithms with particular emphasis on Dehaene's (1992) Triple Code Model, (b) McCloskey's system of autonomous modules, and (c) models detailing both semantic and asemantic routes.

Deloche and Seron's (1982, 1987) well-known model describes a system of asemantic algorithms which allow for the transformation from one code to another (e.g., from arabic numeral to verbal, or vice-versa) without having to consult the meaning of numbers. A magnitude representation code would only be consulted when the task requires it; for example in calculating tasks or in magnitude-comparison tasks. A variant of this model is the Preferred Entry Code Hypothesis (Nöel \& Seron, 1993) which postulates that subjects transform the numerical input into the representation (verbal or arabic) in which they are more skilled. So, subjects whose auditory working memory is superior to their visual memory would use a verbal code, and subjects whose visual memory is better would use a visual code. Integrating aspects of each of these approaches, the Triple Code Model presented by Dehaene (1992) and displayed in Figure 1 hypothesizes that the number processing system operates on three types of codes: (1) visual-arabic, (2) auditory-verbal, and (3) an analogue magnitude representation. The selection of one code or another depends on the type of mental operation required. The visual-arabic code is used mainly to carry out multidigit operations, the auditory verbal code for counting and the analogue magnitude code to carry out magnitude comparisons.

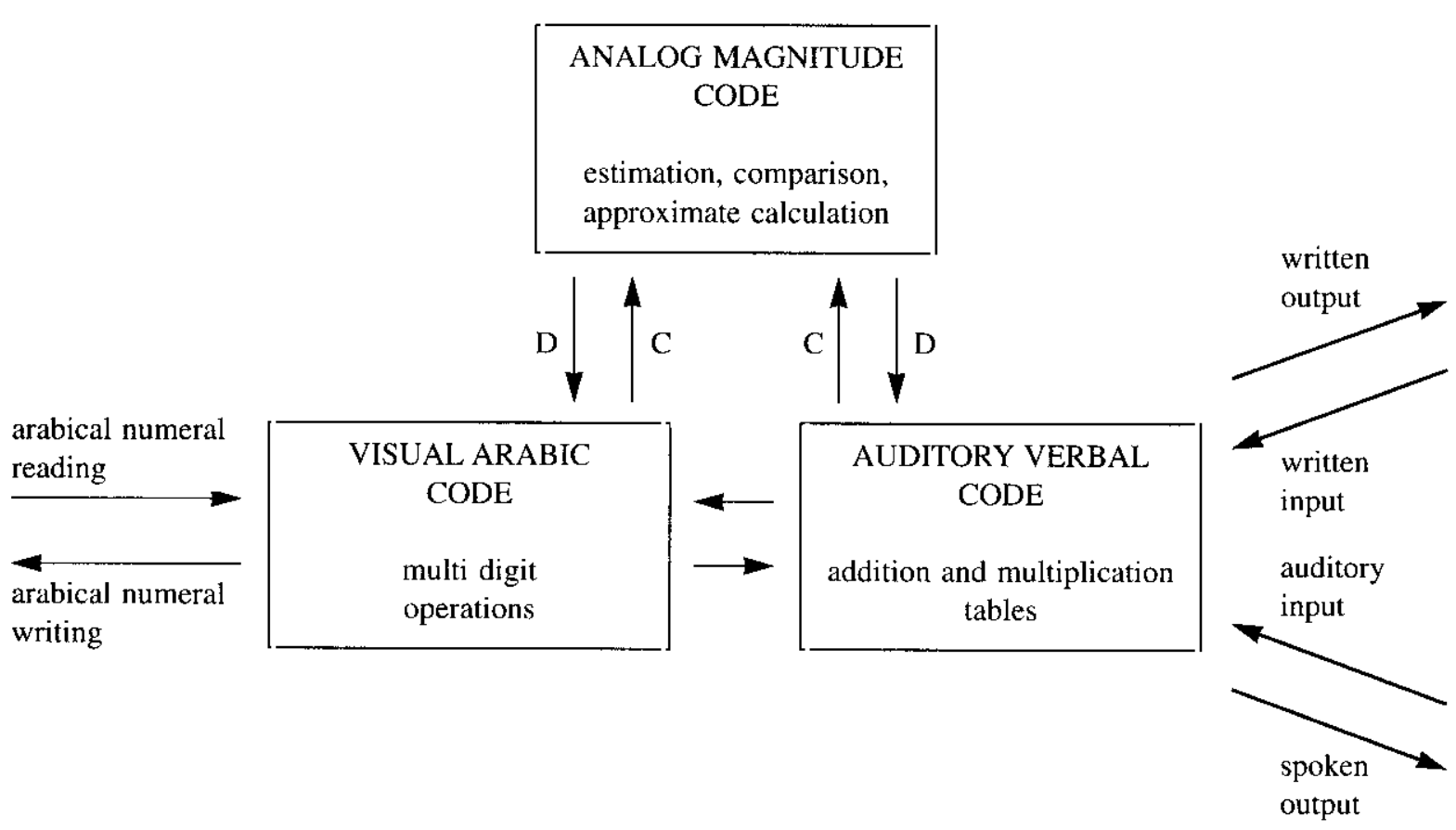

Figure 1. The triple-code model proposed by Dehaene (1992). 
Another well-known model which presents a different view was offered by McCloskey and his collaborators (Macaruso, McCloskey, \& Aliminosa, 1993; McCloskey, 1992; McCloskey \& Caramazza, 1987; McCloskey, Caramazza, \& Basili, 1985; McCloskey, Sokol \& Goodman, 1986; Sokol \& McCloskey, 1988). McCloskey proposed a system made up of different modules which operate autonomously, each one being specialized in a certain function. (See Figure 2.) First, independent numeral comprehension and numeral production mechanisms are postulated, each with different lexical and syntactic processing units. Then, an abstract internal representation takes place between the comprehension and the production processes. In this way, in order to proceed from input to output, no matter what code is used, one must go through the abstract internal representation.

The recent models of Cohen, Dehaene, and Verstichel (1994) and Cipolotti (1995) incorporate both a semantic route, as set forth in the McCloskey model, and an asemantic route such as that proposed by Deloche and Seron (1982, 1987) allowing for the occurrence of certain transformations without access to their meaning. Specifically, in Cipolotti's model (Cipolotti, 1995: Cipolotli \& Butterworth, 1995), shown in Figure 3, two roules are hypothesized for reading arabic numerals whereas Cohen, Dehaene, and Verstichel (1994) offer a 3-route model: surface, asemantic lexical, and "deep" semantic.

\section{CALCULATION MECHANISM}

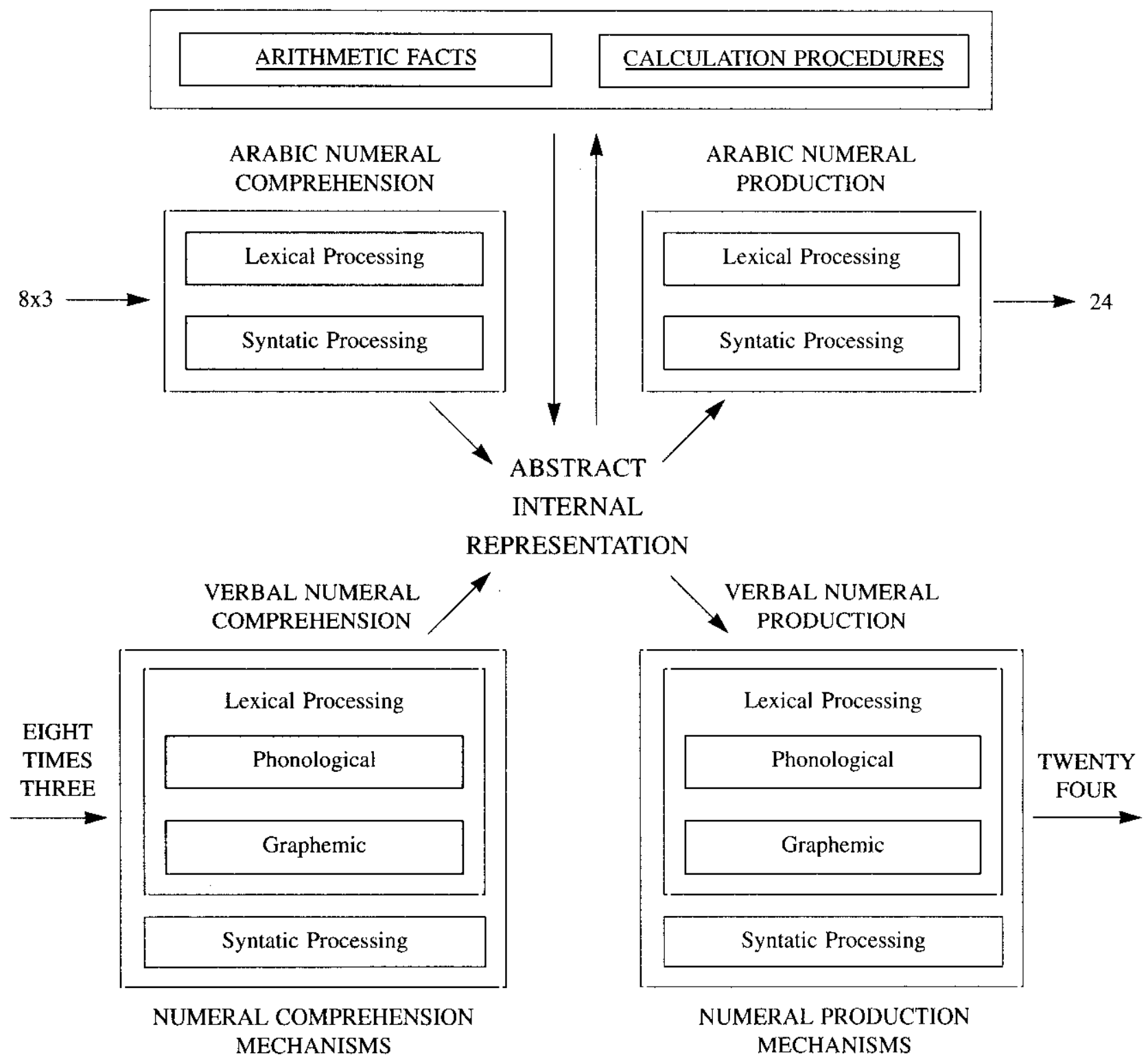

Figure 2. Model proposed by McCloskey, Caramazza and Basili (1985). 


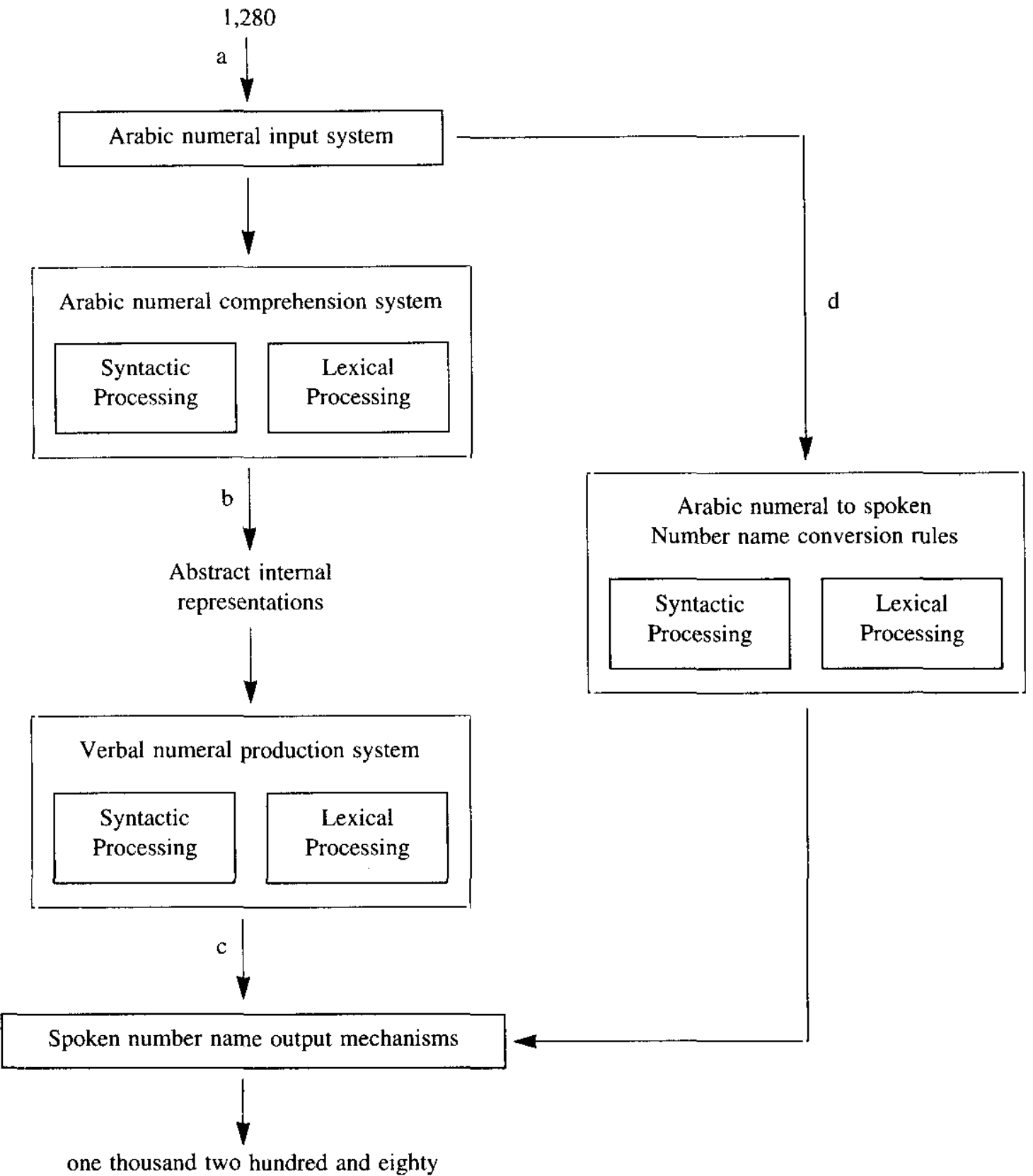

Figure 3. Cipolotti Model (1995).

In short, one may conclude that there are many different models which attempt to explain the number processing system. Some authors defend the existence of a semantic route used in all numerical tasks, while others propose asemantic routes. Yet a third approach includes both types of routes in the model. Regarding another aspect of number processing, some models distinguish between lexical and syntactical processes, whereas other models do not. These are very important theoretical issues from which testable hypotheses can be generated. In this respect, individuals with dyscalculia can provide an excellent source of information.

\section{Relations between Numerical and Linguistic Processing}

Another focus of cognitive neuropsychologists has been the hypothesized relationship between number processing and linguistic processing in general. The hypothesis defended by some authors (most notably, Seron \& Nöel, 1992 ) is that number processing may not be different from the processing of other verbal forms based on the fact that numbers have a lexical component (because simple number forms are represented by words) and a syntactic component 
(because complex numbers are formed by joining simple ones using combinatory rules). However, the arabic numeral lexicon is more reduced than the verbal lexicon and the syntax is simpler (Seron \& Nöel, 1992). Moreover, there are other characteristics that differentiate the arabic and verbal systems, such as the fact that the former is thought to require a previous global processing step (Seron \& Nöel, 1992) whereas the latter does not. Tentatively, one may conclude that two parallel but different systems may be involved.

Data supporting the relationship between the two systems have been found in the study of aphasic patients who usually have problems with numbers, and dyscalculic patients who usually have language problems (Seron \& Nöel, 1992). However, with two exceptions, this relationship has not been empirically demonstrated because most studies have targeted either aphasia or dyscalculia but have not examined both concurrently, so that dissociation between both problems could not be tested. The notable exceptions conducted by Deloche and Seron (1982) and Seron and Deloche (1983) have found that Broca aphasic patients present problems with the syntactic component of numbers whereas Wernicke aphasic present lexical problems with numbers. Nevertheless, no definitive conclusions could be drawn from this research about the function and degree of autonomy for each cognitive process because of insufficient data.

Probably the best way to examine whether we are dealing with different systems is by means of dissociations. A large number of studies have been published which have focused on aphasic patients who are incapable of reading and writing words but who have shown no difficulties with arabic numerals (Anderson, Damasio, \& Damasio, 1990; Rossor, Warrington, \& Cipolotti, 1995). In contrast, fewer cases of patients with no reading problems but with difficulties with arabic numetals have been published. One might deduce from these observations that even though arabic numerals are part of written language in general, they represent written language in its simplest form (similar to the logographic stage of reading, because arabic numerals are really like logographs). In this sense, patients with a slight lesion in the left temporal lobe would have trouble reading words that are more difficult to process, but would not with arabic numerals. However, some cases have been cited in which difficulties are specific to arabic numerals indicating that a double dissociation may exist between reading and writing words and arabic numerals. Cipolotti, Butterworth, and Denes (1991) published a case study in which the patient was diagnosed with severe acalculia for numbers above 4 but who did not have similar difficulties with reading. In Nöel and Seron's (1993) study, a patient read words without difficulty although he could not read nonwords and had trouble with arabic numerals. More recently, Cipolotti (1995) published the case of a patient with Alzheimer's disease who had problems reading arabic numerals but who could read words and nonwords well.

\section{Overview of the Study}

In this paper, we present the case of a patient who had problems in processing numbers in Spanish. We believe this case study is of theoretical interest because his difficulties were greater with numbers than with words. Moreover, the case shows several important dissociations, some of which have not been previously reported, and which may help to clear up some of the doubts surrounding the main number processing models. We believe the findings that are subsequently presented are universal despite the fact that the patient is a Spanish native speaker. Furthermore, the Spanish verbal numerical system is practically identical to that of English and French and it has a similar verbal numerical system and lexical and syntactic components. The lexical one is formed by 28 words: the units (uno, dos, tres, cuatro, cinco, seis, siete, ocho, and nueve) [one, two, three, four, five, six, seven, eight, and nine], the tens (diez, veinte, treinta, cuarenta, cincuenta, sesenta, setenta, ochenta, and noventa) [ten, twenty, thirty, forty, fifty, sixty, seventy, eighty, and ninety], and the multiplicators (cien/cientos, mil and millón/millones) [hundred/hundreds, thousand and million/millions], and the particular words (once, doce, trece, catorce, quince, and quinientos) [eleven, twelve, thirteen, fourteen, fifteen, and five hundred]. When we add the conjunction "y" (and), we have all the necessary words to form any number. There are also some syntactical rules which allow combining the lexical elements into larger units. Thus, number 16 is formed by combining the words for numbers 10 (diez) and 6 (seis): "diez y seis"" (sixteen); 3,468 is expressed in the verbal system as "tres mil cuatrocientos sesenta y ocho" (three thousand four hundred and sixty-eight); and $7,854,261$ as "siete millones, ochocientos cincuenta y cuatro mil, doscientos sesenta y uno" (seven million, eight hundred and fifty-four thousand two hundred and sixty-one).

The study described in this paper is aimed at analyzing the performance of a dyscalculic patient in several linguistic and numerical transcoding tasks in order to get information about the relationship between linguistic and numerical processing. This study further examined the number processing models, in view of the disagreement about the components of the numerical processing system. In this sense, dyscalculic patient results are a good way (perhaps the best) to provide answers to all these questions. Our hypothesis was that our patient would not present similar difficulties in linguistic and numerical processing.

\section{Case Report}

J.T. was a bank employee until he suffered a cerebrovascular accident (CVA) on November 26, 1992, at the age of 61 . The damage was diagnosed as a hemorrhage in the left hemisphere resulting in residual dysphasia. On 
July 19,1993 , he suffered a second CVA with a broad infarction with hemorrhage in the left hemisphere in the area of the middle cerebral artery. At this time his language disturbance was diagnosed as mixed aphasia.

\section{General Evaluation}

In J.T.'s first general evaluation at a neuropsychological clinic, although his performance was within normal limits, he took more time than normal to complete many tasks. He could maintain his attention very well, and, in fact, had no difficulty in visual-spatial tasks or line cancellation. He readily understood and correctly performed both simple and complex commands, such as pointing to the parts of his own body although it was necessary to repeat the more complex commands. J.T. could read without difficulty and understood written instructions. When he was asked to write his name and address, he made no mistakes. However, he had serious problems with number tasks. When he was asked to read a list of arabic numerals or to write, in arabic form, a dictated list of 1- to 3-digit numbers, he had no trouble when reading the list but he made errors when writing (e.g., he substituted some numbers for others--he wrote 14 instead of 18 and 7 instead of 16 )

\section{Method and Related Findings}

\section{Language Examination}

A series of linguistic tasks taken from the Evaluación del Procesamiento Lingüístico en la Afasia (EPLA) (Spanish version of the Psycholinguistic Assessment of Language Processing in Aphasia; PALPA, Valle \& Cuetos, 1995) was administered by one of the authors (G.M.) to J.T. to evaluate the efficiency of different components of his linguistic processing system including (a) matching sounds to letters, (b) letter naming, (c) reading isolated words, (d) naming, (e) repetition, (f) sentence repetition, and ( $g$ ) digit memory. Matching sounds to letters. When presented with 24 items each containing 4 written letters and asked to point to the named letter for each item, J.T.'s performance was perfect ( 24 correct out of 24 possible items).

Letter naming. J.T. had no problems reading letters. He correctly read 25 of 26 letters; his only error was made with the letter " $x$," which is not very common in Spanish.

Reading isolated words. Two list of words taken from the EPLA, one with 40 words and the other with 24 were presented to J.T. to read aloud. His reading score was perfect: 64 correct out of 64 possible.

Naming. J,T, was presented with 40 daily objects pictures (e.g., watch, onion, scissors,...) and asked to name them aloud. He made no errors in performing this task.

Repetition. Next, the 40 words representing the pictures displayed in the previous task were read to J.T. and he was asked to repeat each aloud as they were presented.. His score was 36 out of 40 , slightly lower than the average for normal subjects $(39.82)$, although not statistically different from them (normative data taken from the EPLA; Valle \& Cuetos, 1995). J.T.'s errors did not appear to be the result of failing to remember the word, but because he substituted one phoneme for another ("cinturén" for "cinturón" [belt], "cepigo" for "cepillo" ([brush]).

Sentence repetition. Ten 5- and 6-word sentences (taken from the EPLA) were read aloud, one at a time, to J.T. who was directed to repeat each statement following its presentation by the examiner. Except for small pronunciation errors, J.T. correctly repeated each of the 10 sentences.

Digit memory. In the digit-memory task consisting of asking the patient to repeat series of dictated digits which increased in length. J.T. had considerable difficulties. He correctly repeated 6 out of 102 -digit strings and one of 10 3-digit strings.

\section{Experimental Investigation}

The experimental investigation included number processing, as well as other numerical tasks and writing.

Number processing. In order to find out whether his problems with numbers appeared only with arabic numerals or indicated other modalities (spoken verbal or written verbal), J.T. was presented with a list of 80 numbers requiring a variety of transcoding tasks in several sessions, using a few items per session. The 80 -item list was made up of 201 -digit numbers (each number from 0 to 9 was repeated twice), 20 2-digit numbers, 20 3-digit numbers and 20 4-digit numbers. These numbers were presented to him in three modes (arabic, spoken verbal and written verbal) and J.T. was instructed to express them in one of the three modes for six different transcoding tasks: (1) arabic to spoken verbal, (2) arabic to written verbal, (3) written verbal to spoken verbal, (4) written verbal to arabic, (5) spoken verbal to written verbal, and (6) spoken verbal to arabic. These tasks would allow us to test whether J.T. had specific difficulties in some particular number processing strategy or whether his difficulties occurred in all numerical tasks.

1. Arabic to spoken verbal. The 80 numbers were presented written in arabic form on a page for J.T. to read aloud. His score was 79 correct out of 80 possible. His only error was with the numeral 5832 , which he read as "cincuenta y ocho trescientos dos" ("fifty-eight three hundred two").

2. Arabic to written verbal. As in the previous task, J.T was presented with the same set of numerals but for this task he was instructed to write each numeral in the form of written words. He only managed to write correctly 49 of the 80 stimuli. He correctly wrote all the 1 -digit numbers, made one error in the 2-digit numbers, scored 10 correct out of 20 in the 3-digit numbers, but could write none of the 4-digit numbers. 
3. Written verbal to spoken verbal. When asked to read aloud each of the 80 numbers written with letters, J.T had no problem at all and obtained a perfect score (80/80).

4. Written verbal to arabic. When required to convert written numbers into arabic numerals (e.g., twelve to 12), J.T. had difficulties and scored only 43 correct out of 80 . He obtained 19 of 20 correct for 1 -digits, 15 of 20 for 2 digits, 9 of 20 for 3-digits, and 0 of 20 for 4-digits .

5. Spoken verbal to written verbal. This task consisted of writing dictated numbers in letters (e.g., /ten $\rightarrow$ "ten"). J.T. was correct on 33 out of 80 stimuli. He scored 18 out of 20 for 1-digits, 10 out of 20 for 2-digits, 4 out of 20 for 3-digits, and 1 out of 20 for 4 -digits.

6. Spoken verbal to arabic. This task consisted of writing arabic numbers from dictated numbers (e.g., /ten/ $\rightarrow 10$ ). J.T. was correct on 32 of the 80 stimuli (19 of 201 -digits, 11 of 202 -digits, 2 of 203 -digits, and 0 of 204 -digits).

In Table 1, J.T.'s results in each task are displayed. Statistical analyses employing a series of chi-square tests revealed statistically significant differences only between the spoken verbal output and all other outputs. There were no significant differences obtained between the arabic and the written verbal output. Globally, these were the results; between the written verbal and spoken verbal output $\left(\chi^{2}[1\right.$, $\mathrm{N}=251]=24.60, \mathrm{p}<.001)$ and between arabic and spoken verbal output $\left(\chi^{2}[1, \mathrm{~N}=234]=30.15, \mathrm{p}<.01\right)$.

As J.T. had trouble transcoding both arabic and written verbal numbers, one might conclude that both modes share a common factor. Inspection of the errors made reveals that the characteristics of the difficulties in both modes appear to differ. For example, when the output is arabic numerals, independently of whether the input was presented in spoken verbal or written verbal modes, his mistakes were either lexical (e.g., instead of 68, he wrote 78; instead of 238 , he wrote 228 ; or instead of 1928 , he wrote 1978 ) or reduction of the digit numbers, probably due to short-term memory
(STM) problems (e.g., 314 instead of 3174 , or 987 instead of 9287), especially with 3- or 4-digit numbers. Indeed, if the results for spoken and written input are compared, the number of lexical mistakes was approximately the same in each case ( 20 and 22 , respectively; but the number of reductions was higher when the input was spoken [28] than when it was written [15], because in the former, it is more difficult to retain the number in STM storage).

When the output was written verbal, errors varied, depending on whether the input was presented in spoken verbal or arabic modes. When the input was spoken verbal, J.T's errors were mainly substitution of some graphemes for others which resulted in nonwords (he wrote "dien" instead of "diez," "treza" instead of "trece"), or non-targeted words ("nuevo" instead of "nueve"), or omitting a word. He also made many word-omission errors, probably because of the short-term memory problems mentioned in a previous section. Sometimes J.T. forgot the first part of the number phrase and therefore wrote "tres" instead of "veintitrés" (3 instead of 23); other times he forgot the last word presented (e.g., he wrote "cuarenta" instead of "cuarenta y nueve," 40 instead of 49), although no systematic primacy or recency effects were observed; and, sometimes he formed a new figure with the few numbers he remembered, such as in "trescientos setenta $y$ uno" ("three hundred and seventy-one"), which he reduced to "treinta y uno" ("thirty-one"). In a few cases, he substituted some numbers for others which had no similarity whatsoever (e.g., instead of "quinientos cuarenta y seis" [546] he wrote "setenta y uno" [71]) or he wrote nonwords which did not resemble the stimulus (instead of "dieciseis" [16] he wrote "sentenciamigo" [sentencefriend]).

However, when the input was in arabic numerals, although he also made some letter substitution errors (e.g., "cince" instead of "quince" [15]) and some lexical ones ("quinientas treinta y una" [531] instead of "quinientas veintidos" [522]), his errors were mainly syntactical (e.g., "noventa y cinco"

Table 1

Number of Correct Answers provided by J.T. in the Transcoding Tasks

\begin{tabular}{|c|c|c|c|c|c|c|}
\hline \multirow[b]{2}{*}{ Stimulus form } & \multirow[b]{2}{*}{ Response form } & \multicolumn{4}{|c|}{ Number of digits presented } & \multirow[b]{2}{*}{ Total } \\
\hline & & 1 & 2 & 3 & 4 & \\
\hline Arabic & Spoken verbal & 20 & 20 & 20 & 19 & 79 \\
\hline Written verbal & Spoken verbal & 20 & 20 & 20 & 20 & 80 \\
\hline Total & Spoken verbal & 40 & 40 & 40 & 39 & 159 \\
\hline Arabic & Written verbal & 20 & 19 & 10 & 0 & 49 \\
\hline Spoken verbal & Written verbal & 18 & 10 & 4 & 1 & 33 \\
\hline Total & Written verbal & 38 & 29 & 14 & 1 & 82 \\
\hline Spoken verbal & Arabic & 19 & 11 & 2 & 0 & 32 \\
\hline Written verbal & Arabic & 19 & 15 & 9 & 0 & 43 \\
\hline Total & Arabic & 38 & 26 & 11 & 0 & 75 \\
\hline
\end{tabular}


Table 2

Types of Errors

\begin{tabular}{|c|c|c|c|c|c|c|c|}
\hline \multirow[b]{2}{*}{ Stimulus form } & \multicolumn{7}{|c|}{ Errors } \\
\hline & Response form & lexical & syntactical & reduction & graphemic & no answer & Total \\
\hline Arabic & Spoken verbal & - & 1 & - & - & - & 1 \\
\hline Arabic & Written verbal & 3 & 27 & - & 1 & - & 31 \\
\hline Written verbal & Spoken verbal & - & - & - & - & - & 0 \\
\hline Written verbal & Arabic & 22 & - & 15 & - & - & 37 \\
\hline Spoken verbal & Written verbal & - & - & 7 & 30 & 10 & 47 \\
\hline Spoken verbal & Arabic & 20 & - & 28 & - & - & 48 \\
\hline
\end{tabular}

[95] instead of "nueve mil cinco" [9,005]; "seis noventa y una" [6 91] instead of "seiscientos noventa y una" [691]), or a mixture of lexical and syntactical ones (nuevo y seis" [new and six] instead of "novecientos tres" [903]). In fact, in the 31 errors he made when transcribing from arabic to written verbal, there were 27 syntactical-type errors with 17 of the errors reflecting syntactical errors only while the remaining 10 revealed both syntactical and written errors.

In Table 2, five types of errors committed by J.T. are broken down by stimulus form and by response form.

An examination of J.T.'s performance on each of these tasks suggests that J.T. had difficulties writing numbers but not expressing them orally. Furthermore, his problems in writing numbers in arabic form were different from those he had with written verbal output. In arabic output his errors were mainly lexical in nature, but in written verbal his errors were both syntactical and graphemic. In the task of spoken verbal to written verbal conversion, he made few syntactical errors, because he only had to transcribe the sounds be heard into letters.

Other numerical tasks. From the previous tasks, it was apparent that J.T.'s problems were in written output-processing tasks. Subsequently, several numerical tasks were administered to J.T. in an attempt to define the boundaries of the deficit. These tasks included, (1) Arabic numeral to written number identity matching, (2) Expressing qualities, (3) Reading aloud and then writing arabic numerals, and (4) Calculations.

I. Arabic numeral to written number identity matching. J.T. was presented with 40 pairs of stimuli. In each pair, one arabic numeral and one written number (e.g., 10 and ten, respectively) was shown to J.T. who indicated whether the two stimuli were identical. Half of the stimuli pairs were identical (e.g., 28 -"veintiocho" [twenty-eight]), and half were different ("treinta y dos" [thirty two]- 36). The different pairs all had the same number of digits. Ten of the pairs were made up of 1-digit figures, 10 2-digit ones, 10 3-digit ones, and 10 4-digit ones. J.T.'s performance on this task was strong with a near perfect score of 39 out of 40 .
2. Expressing quantities. To examine J.T.'s ability to express quantities, several trials were employed in which J.T. was asked to count the numbers of round, red cards displayed on a table. The number of cards presented in each trial varied from 1 to 30. J.T. was instructed to express the number of elements in arabic numerals, orally, and in written form. J.T. had no difficulties when expressing the quantity orally $(30$ correct out of 30 possible, but he had trouble when he had to express them in verbal writing ( 24 correct out of 30 ), or when using arabic numerals (22 correct out of 30 ).

His errors were simjlar to those produced in the transformation tasks. Thus, in arabic expression, his errors were of the lexical type (11 instead of 12, 18 instead of 19), and in written verbal expression there were two lexical errors ("catorce" [fourteen] instead of "doce" [twelve]), two syntactical ones ("siete" [seven] instead of "seventeen" [seventeen]), one syntactical, an omission of one grapheme ("veintidós y cuato" instead of "veinticuatro" [twenty-four]), and one that was difficult to classify ("veinte y treinta" [twenty and thirty] instead of "treinta" [thirty]).

3. Reading aloud and then writing arabic numerals. In order to examine whether his difficulties with numbers were because of memory problems, J.T. was asked to make a double transformation, which required the recall of numbers after a few seconds. He was presented with 40 cards, each with one printed arabic number (10 1-digit numbers, 102 digit ones, 10 3-digit ones, and 10 4-digit ones) to read aloud; and, after each card was removed, he was instructed to write it as an arabic numeral. J.T. made no mistakes on this task ( 40 correct out of 40 ), which indicated he was capable of retaining the numbers in his short-term memory (STM); although, when he was directed to write arabic numerals under other conditions, he made mistakes.

4. Calculations. A series of written operations of addition, subtraction, multiplication and division, using arabic figures were presented to J.T.

When asked to perform additions without carrying, J.T. had few problems, of 28 additions of 1-, 2-, 3- and 4-digit 
figures (e.g., $604+192$ ), he failed only twice (both times when given 3-figure addition problems). His performance was, therefore, practically normal: 26 correct of 28 . However, when he had to carry (e.g., $685+829$ ), he performed considerably less accurately (2/8), mainly because he did not remember the carried numbers, or he carried a larger number (e.g., $385+427=912$ instead of 812).

Subtraction appeared to be more difficult for him. When the problem did not require a number to be carried (e.g., $795-461$ ), he scored 16 correct out of 32 ; but when he did have to carry (e.g., $761-495$ ), his performance was always incorrect (0/16). His errors occurred mainly when the task was to subtract a greater number from a smaller one and then borrow from a $10 \mathrm{~s}$ or 100 s column (e.g., $591-322=$ 278 instead of 269 ).

In multiplication tasks, J.T. was presented with a series of problems in which a 1 - to 4-digit number was multiplied by a single-digit number (e.g., $761 \times 8$ ). His performance was correct on only 5 of 24 problems. His errors consisted of applying the multiplication table incorrectly (e.g., $7 \times 4$ $=14$ ), or adding instead of multiplying $(3 \times 9=12)$, or for other reasons which we could not verify ( $76 \times 4=198$ ).

Finally, for the division tasks, he was presented with a dividend of one to four digits with a divisor which was always a 1-digit number (e.g., 736:4). J.T. was able to correctly perform only 2 of 16 trials. He made a variety of mistakes. Sometimes he said out loud one figure and wrote another, although neither of them was the right one; other times, he omitted one of the digits of the dividend (e.g., 6:2 $=3$, instead of $36: 2$, he omitted the number 3 ).

Writing. In order to examine whether J.T.'s writing problems were limited to numbers or also involved language, we set him five writing tasks: (1) Writing dictated words, (2) Writing dictated nonsense syllables, (3) Writing the names of pictures, (4) Writing letters, and (5) Sentence writing.

1. Writing dictated words. Of a list of 24 words, all of them bisyllabic but with a different number of letters, J.T. only wrote 14 correctly. The most frequent error was confusing one letter so that the words were not only misspelled but generated nonsense syllables in Spanish. In 7 of 24 words presented, J.T. made substitutions of one letter for another ("bundo" instead of "mundo" [world], "lipro" instead of "libro" [book]), letter additions in 2 ("ribo" instead of "rio" [river], "otoro" instead of "toro" [bull]), and just 1 omission ("balco" instead of "balcón" [balcony]). His mistakes were similar to those he made when writing numbers in the written verbal form and were because of a deficit in his allographic stage, which is discussed in greater detail in a subsequent section.

2. Writing dictated nonsense syllables. With a similar list of nonsense syllables (created by changing one letter from each word in the previous task), J.T. made similar mistakes, but performed even more poorly (4 correct out of 24). Most of his errors were also with one or two letters. He made 12 substitutions ( 6 of which were lexicalizations: "tiempo" [time] instead of "tienfo"; "plato" [dish] instead of "plaba"), 3 additions ("rubo" instead of "ruo"), and 5 errors that were difficult to classify, as they bore little resemblance to the target ("baro" instead of "gapel").

3. Writing the names of pictures. In order to examine the possibility that J.T.'s writing errors were because of a problem in discriminating certain phonemes (because his errors consisted in letter substitutions), he was given a third writing task. This time, instead of dictating the words, he was presented with pictures and asked to write their names. He only scored 17 correct out of 40 , and his errors were similar to those that he made in the two previous tasks: 14 letter substitutions, 2 omissions, 2 additions, 1 exchange, 1 incomplete word and three errors that were difficult to classify.

4. Writing letters. As J.T.'s writing errors always consisted of mistaking one letter for another in a word, 27 isolated letters were dictated for him to write. He only managed to write 6 correctly. Twice he wrote a similar letter ("u" instead of " $\mathrm{v"}$ ", and "c" instead of " $\mathrm{q}$ ") and in the other cases he tried to write complete words - although he only managed this on two occasions ("la ceta" instead of " $\mathrm{z}$ ", "ge" instead of "g", as that is the way they are pronounced). In the other cases, he wrote words which only slightly resembled the name of the letters ("vina" instead of "b" or "lete" instead of " $t$ ").

5. Writing sentences. In order to examine whether part of J.T.'s writing problems with multi-digit numbers were due to STM., sentences formed by several words were dictated to him. Five sentences were dictated, all of them with a subject-verb-object structure, and with five or six words (e.g., "El toro persigue al perro" [the bull chases the $\operatorname{dog}]$ ), as this is the average length of the four-digit numbers with which he had so much trouble. J.T. was totally incapable of writing a complete sentence. He generally wrote the first word correctly and then made up the rest (e.g., instead of "El toro persigue al perro" [the bull chases the dog], he wrote "El toro eqtarmino" [the bull eqtarmino(no translation)]; instead of "El ratón ataca al gato" [the mouse attacks the cat], he wrote "Ratón tener mucho tiempo" [Mouse to have plenty of time]). Obviously, memorylimitations influenced his performance but cannot explain the fact that the phrases used in this task were of a similar length to those used in the repetition task, in which he performed perfectly. Certainly, J.T. had trouble writing, which affected numbers when he had to express them in words, as well as language in general.

\section{Discussion}

In the present paper, number processing was investigated in a patient, J.T., who had suffered a CVA in the left hemisphere. As a result of his lesion, J.T. conserved his cognitive and linguistic abilities relatively well, but had serious problems processing numbers and performing arithmetical tasks. He also showed severe STM deficits which made his handling of numbers even more difficult. 
This current circumstance was evident by his performance of addition and subtraction problems, in which he always forgot the number he had to carry. As we have shown throughout this paper, J.T.'s problems with numbers could not be reduced to only a problem of memory, but were also related to specific problems in number processing. The fact that he could repeat sentences containing a greater number of words than that of the numbers (which he was unable to process) and, yet, had trouble with numbers formed by just two words, favors this interpretation. This view is also supported by the fact that J.T, could read aloud and then write the corresponding arabic numerals even with 4-digit numbers ( which have a length of at least four words).

The analysis we have made of this patient's case allows us to posit a series of interesting theoretical considerations. First, this patient's performance contradicts the anatomical and functional model of number processing proposed by Dehaene and Cohen (1995) who described a mechanism responsible for processing arabic numerals that is represented in both hemispheres. Our patient had difficulties with arabic numerals and yet only his left hemisphere appeared to be damaged. As his difficulties were only in output, one might speculate that it is not his visual arabic system which was damaged but the written output which could be localized in the left hemisphere. However, in this case, the arabic input system would have to be differentiated from the output system, as in the model of McCloskey, Caramazza, and Basili (1985), which makes a distinction between independent mechanisms of numeral comprehension and production. With a separation of this kind, the input system should be situated in both hemispheres (or only in the right hemisphere), whereas the output system would be in the left hemisphere. It is precisely the dissociations and double dissociations between patients and tasks, which allow us to separate the cognitive and anatomical components of the processes which take part in number processing.

\section{Main Dissociations}

The primary purpose of this research was to analyze the dissociations exhibited by J.T. within the framework of existing models. Because J.T.'s problems with numbers are very specific, the dissociations he shows are varied, and some of them have not been reported previously. These dissociations have not been included in the previous discussion of dissociations that fit existing models of the cognitive processes underlying number processing. Therefore, the details of these new dissociations are discussed in this section.

To begin with, a critical dissociation shown by J.T. was between arabic numeral and linguistic processing. Although he had difficulties in both activities, these tasks are of a different nature. For example, when writing arabic numerals, he predominantly made lexical errors (also reduction errors, probably because of memory difficulties) in written verbal output whereas his errors (besides general writing problems) were mainly syntactical. This dissociation between arabic numerals and language is not new, as it has been described on previous occasions (Anderson et al., 1990; Benson \& Denckla, 1969; Rossor et al., 1995), but this case adds another piece of information. J.T's difficulties affected only production and, more specifically, written production. Another clear dissociation J.T. revealed was between comprehension and production, because he could read numbers but had problems in producing them. Specific problems in writing arabic numerals have been reported over 60 years ago (Singer \& Low, 1933). One of the most well-known cases is that reported by McCloskey et al. (1985) in which the patient read numbers correctly whether presented in arabic or verbal form and yet had problems writing them in arabic form. More recently, patients described by Cipolotti et al. (1994), and by Nöel and Seron (1995), reportedly have had problems writing arabic numerals despite having little trouble reading the words. All these patients (as well as J.T.) exhibited a double dissociation. However, the patients reported by Benson and Denckla (1969), Nöel and Seron (1993), and Cipolotti (1995), suffered the opposite problem because they had problems understanding arabic numerals but could produce them correctly.

Within the production system, another interesting dissociation produced by J.T. was that between arabic and verbal outputs. The relationship between these two outputs has been well documented by Deloche and Seron (1982) and Seron and Deloche (1983). Seron and Deloche (1987) suggested that arabic output must be easier than verbal output, as a group of aphasic patients they had studied found it easier to write in arabic numerals. But one must not overlook the fact that these patients were aphasic and that their greater difficulties with verbal material were expected. In the case of our patient, J.T., the problems were with arabic production, indicating that it was not simply a case of greater difficulty with verbal production but rather different processes which may have been damaged independently. In fact, J.T. exhibited a double dissociation as compared with the Wemicke aphasic patient cited by Seron and Nöel (1992), who could write numbers in arabic form but had difficulties expressing them in the verbal written form, in contrast to J.T. who wrote numbers in verbal form but had difficulties writing them in arabic form.

A third dissociation was observed in J.T.'s production of written verbal and spoken verbal outputs at the lexical level. The patients H.Y. (studied by McCloskey et al., 1986) and J.S.(studied by Mccloskey, Caramazza \& GoodmanShulman , 1990) had more severe problems with spoken verbal output than with written verbal output. Our patient, J.T., as well as the patient reported by Macaruso et al. (1993), however, had more severe problems with written verbal output than with spoken verbal production.

Apart from these dissociations, which are of theoretical interest, the results observed in our patient allow for finer 
dissociations between the modules that make up the different output modalities. For example, a very interesting dissociation was that found within the arabic production system between its lexical and syntactical components. Whereas our patient, J.T., exhibited some lexical difficulties when transcoding arabic numerals, the cases of V.O. (reported by Caramazza \& McCloskey, 1994) and of D.M. (reported by Cipolotti et al., 1994) presented primarily syntactical difficulties in arabic numeral output. Both V.O. and D.M. exhibited a single dissociation in contrast to J.T.'s double-dissociation production. These behaviors led us to consider the lexical and syntactical processes of the arabic output as independent.

In addition, consider the dissociation observed between lexical and syntactical processes in verbal output. There have already been reports of some patients showing a dissociation between lexical and syntactical processes of oral output. McCloskey et al. (1990) reported one case (J.E.) with a syntactical level disorder and another one (A.T.) with a lexical disorder. A similar process probably occurs in the written verbal expression output, because the patients J.E. (studied by McCloskey et al.) and our own had problems at the syntactical level, whereas the patient P.H. (studied by Macaruso et al., 1993) presented problems at the lexical level.

A final consideration is the dissociation of the syntactical aspects of spoken verbal and written verbal output. This dissociation is particularly noteworthy because, as in McCloskey's model (Macaruso et al., 1993; McCloskey, 1992; McCloskey \& Caramazza 1987; McCloskey et al., 1985; McCloskey et al., 1986; Sokol \& McCloskey, 1988), the syntactical component is proposed to be a common mechanism for both spoken and written output which indicates that if a patient has syntactical problems, he or she should reveal them in both modalities. Mc Closkey's support for his model is provided by the Sokol and McCloskey (1988) patient, J.S., who had syntactical problems both in oral and written output, but had lexical problems only in oral production, which lead them to suppose that the syntactical component is common and the lexical one specific. However, our patient, J.T., shows syntactical problems in writing but not in oral language, which suggests that there are separate systems involved. For instance, although J.T. can express perfectly arabic numerals orally, such as 691 (seiscientos noventa y uno) and 4700 (cuatro mil setecientos), when he was instructed to write them, he made syntactical mistakes (seis noventa y uno [six ninety-one] and cuatro setenta y cero [four seventy and zero]). In many cases, it is assumed that these errors do not reflect STM problems because no number is omitted but rather they are simply incorrectly combined.

It is our opinion that the observations based upon the performance of our patient, J.T., offers an important piece in the difficult task of completing the puzzle of the cognitive processes that intervene in number processing. The findings suggest several restrictions when confronted with the task of creating an explicative numerical processing model. The most important ones are (a) the dissociation between the lexical and the syntactical component in the arabic numeral production and (b) the separation of the syntactical component in the written and spoken verbal outputs.

\section{Adjustment to the Models}

We shall now examine how these dissociations can be interpreted by the main models of number processing.

As we indicated previously in McCloskey's model (Macaruso et al., 1993; McCloskey, 1992; McCloskey \& Caramazza 1987; McCloskey et al., 1985; McCloskey et al., 1986; Sokol \& McCloskey, 1988) emphasis is placed on a singular syntactic component in the verbal production system common to both the written and spoken forms. Consequently, in order to explain the syntactical difficulties exhibited by J.T. when writing words for numbers, even though he had no trouble naming them orally, the McCloskey model would need to be revised to include two complete verbal production systems, one oral and one written, both possessing lexical and syntactical components. With this small extension, the model could account for J.T.'s difficulties perfectly. The observed deficit would be located in the arabic lexical output and in the verbal written syntactical output.

Cipolotti's model (1995) would also require the addition of a new component to explain J.T.'s data. This model does envisage a verbal production system with both components, lexical and syntactical, but only makes specific reference to spoken language. It would, therefore, be necessary to add another similar component for written language (and of course, another for arabic numerals). With these characteristics added to Cipolotti's model, the explanation would be similar to that offered for the revised McCloskey model (even though, in this case, the asemantic route appears).

For Deloche and Seron's model $(1982,1987)$ to apply to the case of J.T., an additional question must be taken into consideration besides the distinctions between lexical and syntactical components. The fact that J.T. committed the same kind of mistakes in the transcodification tasks (from verbal to written) and in the tasks where the input is the meaning (to express quantities), implies that the mechanisms at work in both tasks are probably the same. One possible explanation is that the task of expressing quantities in writing is accomplished through verbal mediation; that is, the quantities would first be expressed in verbal form, and then the transcodification algorithm would be applied from verbal to arabic in some cases, and to writing in others (Nöel \& Seron, 1995).

All in all, we may conclude that, with the suggested additions to the different models, a more complete model that includes all the dissociations described in this paper would include the characteristics of the one that appears in Figure 4. 


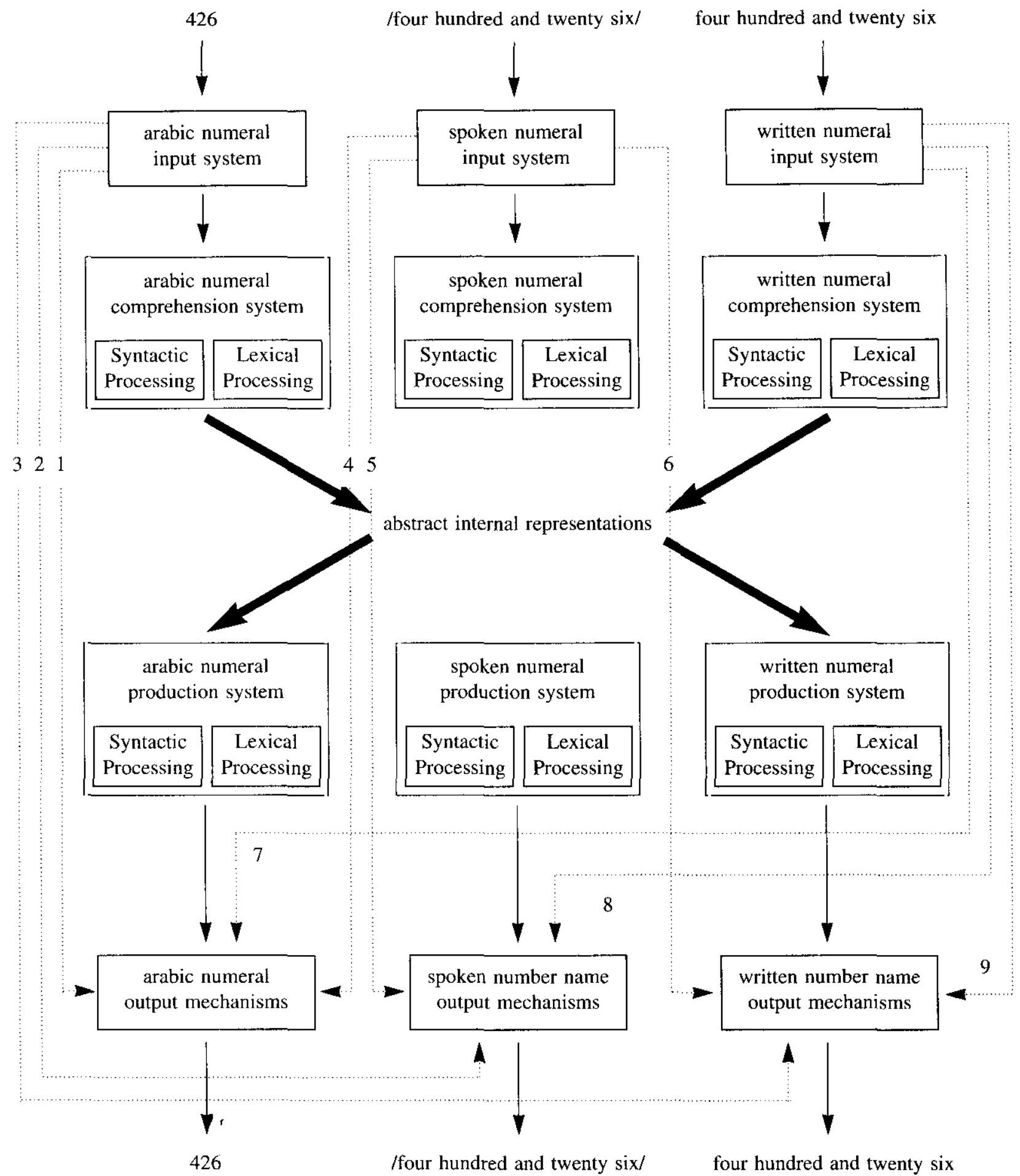

ASEMANTIC ROUTES:

1. copy (arabic to arabic)

2. arabic numeral to spoken name

3. arabic numeral to written name

4. spoken name to arabic numeral

5. repetition
6. phonology to orthography

7. written name to arabic numeral

8. orthography to phonology

9. copy (orthography to orthography)

Figure 4. Proposed Model. 
As depicted in Figure 4, asemantic routes are represented by a broken line, because in this paper no supporting evidence has been forthcoming.. However, there appears to be a fair amount of data that has been recently published by Seron and Nöel (1995) which challenge the asemantic route hypothesis. In fact, the explanation of our patient's problem would be simpler without the existence of asemantic routes, simply proposing that the deficit is in the lexical component of the arabic system and in the syntactical one of the verbal written output (such as we have described). To assume the existence of these routes would require the supposition that they, too, are damaged; although a possible explanation that allows both routes to be preserved is that the activation of one inhibits the use of the other, as Cipolotti (1995) maintains. In any case, we do not have sufficient data in this research to address the question of whether asemantic routes are necessary or not.

In the model presented in Figure 4, J.T.'s difficulties would be located in the following three processes:

1. In the arabic output lexicon: As J.T.'s errors when writing arabic numerals are mainly of the lexical type, we are led to believe that his deficiency lies in an output lexicon that is specific to arabic numerals because he has no problems producing lexical forms in other output modalities.

2. In the written output syntax: When J.T. has to write a number using words he makes many syntactical mistakes, which indicates that he has problems with retrieving number writing rules. We propose that these rules are specific to writing numbers in the verbal form, as no similar errors appear in writing arabic numerals, or in the oral production of verbal numbers.

3. In the allograph recovery system: Another problem that appears in J.T.'s writing of numbers in verbal form (and this applies to any kind of writing, including words and nonsense syllables), is that of the confusion of graphemes. This difficulty appears in a later stage than the lexical one, in what Ellis (1982) referred to as "allograph retrieval in writing" and so it would appear in any written production, be it words, nonwords, or numbers in verbal form.

In short, the patient described in this study exhibits some interesting dissociations when comparing his own performances on various tasks and when compared with other patients, which cannot be explained by current number processing models. The main dissociations are between lexical and syntactical processes in arabic output and between spoken verbal and written verbal outputs at the lexical level. These data are not contemplated by existing models but can be explained with the model we have proposed in Figure 4, which incorporates semantic and asemantic routes into the same framework and which draws a distinction between lexical and syntactic components in arabic, spoken verbal, and written verbal systems.

\section{References}

Anderson, S.W., Damasio, A.R., \& Damasio, H. (1990). Troubled letters but not numbers. Brain, 113, 749-766.

Benson, D.F, \& Denckla, M.B. (1969). Verbal paraphasia as a cause of calculation disturbances. Archives of Neurology, 21, 96-102.

Caramazza, A., \& McCloskey, M. (1994). Number system processing: Evidence from dyscalculia. In N.Cohen, $\mathbf{M}$. Schwart7, \& M.Moscovitch (Eds.), Advances in Cognitive Neuropsychology. New York: Guilford Press.

Cipolotti, L. (1995). Multiple routes for reading words, why not numbers? Evidence from a case of arabic numeral dyslexia. Cognitive Neuropsychology, 12, 313-342.

Cipolotti, L., \& Butterworth, B. (1995). Toward a multiroute model of number processing: Impaired number transcoding with preserved calculation skills. Joumal of Experimental Psychology: General, 124, 375-390.

Cipolotti, L., Butterworth, B., \& Denes, G. (1991). A specific deficit for numbers in case of dense acalculia. Brain, 1/4, 2619-2637

Cipolotti, L., Butterworth, B., \& Warrington, E.K. (1994). From "one thousand nine hundred and forty-five" to 1000,945 . Neurospychologia, 32, 503-509.

Cohen, L., Dehaene, S., \& Verstichel, P. (1994). Number words and number non-words. A case of deep dyslexia extending to arabic numerals. Brain, 117, 267-279.

Dehaene, S. (1992). Varicties of numerical abilities. Cognition, 44, $1-42$.

Dehaene, S., \& Cohen, L. (1995). Towards an anatomical and functional model of number processing. Mathematical Cognition, 1, 83-120.

Deloche, G., \& Seron, X. (1982). From Three to 3: A differential analysis of skills in transcoding quantities between patients with Broca's and Wernicke's aphasia. Brain, 105, 719-733.

Deloche, G., \& Seron, X. (1987). Numerical transcoding: A general production model. In G. Deloche \& X. Seron (Eds.), Mathematical disabilities: A cognitive neuropsychological perspective. Hillsdale, NJ: Lawrence Erlbaum Associates.

Ellis, A.W. (1982). Spelling and writing (and reading and speaking). In A.W. Ellis (Ed.), Normality and pathology in cognitive functions. London: Academic Press.

Macaruso, P., McCloskey, M., \& Aliminosa, D. (1993). The functional architecture of the cognitive numerical processing system: Evidence from a patient with multiple impairments. Cognitive Neuropsychology, 10, 341-376.

McCloskey, M. (1992). Cognitive mechanisms in numerical processing: Evidence from acquired dyscalculia. Cognition, 44, $107-157$.

McCloskey, M., \& Caramazza, A. (1987). Cognitive mechanisms in normal and impaired number processing. In G. Deloche \& X. Seron (Eds.), Mathematical disabilities: A cognitive neuropsychological perspective. Hillsdale, NJ: Lawrence Erlbaum Associates.

McCloskcy, M., Caramazza, A., \& Basili, A. (1985), Cognitive mechanisms in number processing and calculation: Evidence from dyscalculia. Brain and Cognition, 4, 171-196. 
McCloskey, M., Caramazza, A., \& Goodman-Schulman, R.A (1990). Cognitive representations and processes in number production: Evidence from cases of acquired dyscalculia. In A. Caramazza (Ed.), Cognitive Neuropsychology and Neurolinguistics. Hillsdale, NJ: Lawrence Erlbaum Associates.

McCloskey, M., Sokol, S.M., \& Goodman, R.A. (1986). Cognitive processes in verbal-number production: Inferences from the performance of brain-damaged subjects. Journal of Experimental Psychology: General, 115, 307-330.

Nöel, M.P., \& Seron, X. (1993). Arabic number reading deficit: a single case study or when 236 is read (2306) and judged superior to 1258. Cognitive Neuropsychology, 10, 317-339.

Nöel, M.P., \& Seron, X. (1995). Lexicalization errors in writing arabic numerals: a single-case study. Brain and Cognition, 29, 151-179.

Rossor, M.N., Warrington, E.K., \& Cipolotti, L. (1995). The isolation of calculation skilss. Journal of Neurology, 242, 78-81.

Seron, X., \& Deloche, G. (1983). From 4 to four: a supplement to 'From three to 3'. Brain, 106, 735-744.

Seron, X., \& Deloche, M.P. (1987). The production of counting sequences by aphasics and children: $A$ matter of lexical processing? In G. Deloche \& X. Seron (Eds.), Mathematical disabilities: A Cognitive Neuropsychological perspective. Hillsdale, NJ: Lawrence Erlbaum Associates.

Seron, X., \& Nöel, M.P. (1992). Language and numerical disorders: A neuropsychological approach. In J. Alegria, D. Holender, J. Morais, \& M. Radeau. (Eds), Analytic Approaches to Human Cognition. North-Holland: Elsevier Science Publishers B.V.

Seron, X., \& Nöel, M.P. (1995). Transcoding numbers from the arabic code to the verbal one or vice versa: How many routes? Mathematical Cognition, 1, 215-243.

Singer, H.D., \& Low, A.A. (1933). Acalculia: A clinical study. Archives of Neurology and Psychiatry, 29, 467-498.

Sokol, S., \& McCloskey, M. (1988). Levels of representation in verbal number production. Applied Psycholinguistics, 9, 267-281.

Valle, F., \& Cuetos, F. (1995). EPLA: Evaluacion del Procesamiento Linguistico en la Afasia. Hillsdale, NJ: Lawrence Erlbaum Associates.

Received May 16, 1997 Revision received December 1, 1997 Accepted February 12, 1998 